\title{
Effect of high-fat feeding on metabolic efficiency and mitochondrial oxidative capacity in adult rats
}

\author{
Susanna lossa, Lillà Lionetti, Maria P. Mollica, Raffaella Crescenzo, Monica Botta, \\ Antonio Barletta and Giovanna Liverini ${ }^{\star}$ \\ Department of General and Environmental Physiology, University of Naples 'FEDERICO II', Via Mezzocannone 8, \\ I-80134 Napoli, Italy
}

(Received 20 December 2002 - Revised 23 May 2003 - Accepted 18 June 2003)

\begin{abstract}
The changes in metabolic efficiency, body composition, and nutrient partitioning induced by high-fat feeding were evaluated in adult rats ( $90 \mathrm{~d}$ of age). The alterations in serum free triiodothyronine, insulin, and leptin levels, as well as in hepatic and skeletal muscle metabolism, were also assessed. Rats were fed either a low- or a high-fat diet for 2 weeks. Relative to the low-fat feeding, energy intake and expenditure, as well as body-energy gain, lipid gain, and energetic efficiency, were increased by the high-fat feeding. Increased serum leptin levels accompanied these variations. A positive correlation between serum leptin levels and percentage of body fat was found in the rats fed the low- or high-fat diet, with a significant divergence between the slope of the regression lines. Furthermore, a negative correlation between serum leptin level and energy intake was found in the rats fed the low-fat diet, while a positive correlation was found in the rats fed the high-fat diet. Finally, the high-fat feeding decreased the hepatic and skeletal muscle mitochondrial oxidative capacity. It is concluded that, in adult rats, a nutritional factor such as a high level of fat in the diet induces obesity, leptin resistance, and impairment of mitochondrial capacity, all phenomena typical of unrestrained aged rats.
\end{abstract}

Energy balance: Mitochondrial capacity: Triiodothyronine: Leptin

The prevalence of obesity is increasing in most countries around the world (World Health Organization 1998). To develop effective prevention strategies, it is important that the causes of weight gain are understood. Among the factors leading to the development of obesity, diet composition is certainly of importance (McCrory et al. 2000). In fact, it is known that diets rich in fat are generally associated with the development of obesity (Smith et al. 1998; Hill et al. 2000). However, it has been previously shown that post-weaning (about 30-d-old) and post-pubertal (about 50-d-old) rats fed a high-fat diet for 2 weeks exhibit increased energy intake associated with increased energy expenditure, which exceeds the obligatory cost of energy gain (Liverini et al. 1996; Iossa et al. 1999a). This regulatory increase in thermogenic capacity counteracts obesity development completely in post-weaning rats but only in part in post-pubertal rats, thus suggesting a weakness of regulatory responses to increased fat intake during growth. It has also been shown that, with increasing age, even rats fed a low-fat diet developed a spontaneous obesity (Barzilai \& Rossetti, 1995). In agreement, it has previously been shown that in adult rats (aged between 90 and $180 \mathrm{~d}$ ), which are characterised by the cessation of growth and development, ingested energy is higher than expenditure and the excess is entirely stored as fat rather than burnt (Iossa et al. 1999b).

Taking into account these observations, it was considered of interest to evaluate the changes in energy balance following overfeeding on a high-fat diet for 2 weeks in adult rats (90 d of age), which are potentially prone to developing obesity.

The changes in energy expenditure found at the wholebody level reflect the changes in metabolic activity of single organs and tissues, especially those that are the main contributors to total metabolism, for example the liver and muscle (Rolfe \& Brown, 1997). Since mitochondria are the main site of the oxidative process, changes in cellular metabolic activity could result from changes in mitochondrial mass and/or specific capacity. In fact, it has previously been found that decreased hepatic metabolic efficiency and increased skeletal muscle capacity to oxidise lipid substrates contributes to regulatory responses elicited by high-fat feeding in very young rats (Iossa et al. 1995, 2002). It was considered, therefore, of interest to determine the muscle and liver mitochondrial oxidative capacity in adult rats fed a high-fat diet.

Finally, to obtain information on the hormonal modifications induced by high-fat feeding in adult rats, leptin,

\footnotetext{
Abbreviations: $\alpha$-GPDH, $\alpha$-glycerophosphate dehydrogenase; BSA, bovine serum albumin; HEPES, N'-(2-hydroxyethyl)piperazine-N-2-ethanesulfonic acid; ME, metabolisable energy; NEFA, non-esterified fatty acids; $\mathrm{T}_{3}$, triiodothyronine.

* Corresponding author: Professor Giovanna Liverini, fax +39 081 2535090, email liverini@unina.it
} 
insulin, and free triiodothyronine $\left(\mathrm{T}_{3}\right)$ serum levels have been determined. In fact, it is well known that these hormones are important regulators of body weight, energy expenditure and food intake (Danforth \& Burger, 1989; Freake \& Oppenheimer, 1995; Friedman 2002; Leibel, 2002; Porte et al. 2002), and their serum levels are related to age (Iossa et al. 1999b, 2001; Kumar et al. 1999).

\section{Methods and materials}

\section{Animals and diets}

Male Wistar rats aged 90d (Charles River Italia, Calco, Como, Italy) were caged singly in metabolism cages in a temperature-controlled room $\left(24 \pm 1^{\circ} \mathrm{C}\right)$ with a $12 \mathrm{~h}$ light-dark cycle (07.00-19.00 hours). The rats were divided into three groups each composed of eight rats, with similar mean body weight (400 (SE 1) g) and with body weight normally distributed within each group. The treatment, housing, and killing of animals met the guidelines set by the Italian Health Ministry.

At the start of the study, one group of rats was killed to establish baseline measurements. The other two groups of rats were fed a low-fat diet or a high-fat diet for 2 weeks. The high-fat diet was formulated to differ from the low-fat diet only in the fat and carbohydrate contribution to the energy value but to be identical in terms of protein, vitamins, minerals, and fibre, as previously reported (Iossa et al. 2002). In the experimental period body weights and food intakes were monitored daily. Food spilled was carefully collected and accounted for in the food intake calculations. Faeces and urine were also collected daily, dried, and ground to a powder before the determination of their energy content with a bomb calorimeter calibrated with dry benzoic acid as a standard (Parr adiabatic calorimeter; Parr Instruments Co., Moline, IL, USA). Metabolisable energy (ME) intake was obtained by subtracting the energy measured in the faeces and urine from the gross energy intake, determined from daily food consumption and the gross energy density of the diets.

\section{Determination of energy expenditure and energetic efficiency}

At the end of the diet treatment, the animals, without any food deprivation, were anaesthetised by injection of chloral hydrate $(40 \mathrm{mg} / 100 \mathrm{~g}$ body weight, intraperitoneally) and blood was taken via the inferior cava vein. Immediately after blood collection, the liver and hind-leg muscles were removed for preparation of homogenate and isolated mitochondria. Then, the rat carcasses were used for the determination of body energy content, as previously reported (Iossa et al. 1999a). Briefly, this parameter was measured with the bomb calorimeter on samples of carcass homogenised with a mass of water equal to twice the carcass weight in a Polytron homogeniser (Polytron Kinematica AG, Littau/Lucerne, Switzerland) and desiccated at $70^{\circ} \mathrm{C}$ in a vacuum oven. To take into account the energy content of the hind-leg skeletal muscle and the liver, samples of muscles and liver were dried and then the energy content measured with the bomb calorimeter.
Body energy gain was obtained as the difference between the final body energy content and the initial body energy content of the rats killed at the beginning of the experiment. Energy expenditure over the entire experimental period was calculated from the difference between $\mathrm{ME}$ intake and energy gain, while gross energetic efficiency was calculated as the percentage of body energy retained per ME intake. The cost of storage was determined by using the coefficient $1.25 \mathrm{~kJ} / \mathrm{kJ}$ (Pullar \& Webster, 1977) for protein and $0.36 \mathrm{~kJ} / \mathrm{kJ}$ (low-fat diet; Pullar \& Webster, 1977) or $0 \cdot 16 \mathrm{~kJ} / \mathrm{kJ}$ (high-fat diet; Rothwell et al. 1985) for fat. Net energy expenditure was obtained by subtracting the cost of fat and protein storage from total energy expenditure.

\section{Body composition measurements}

Water content was determined by the difference in weight of the carcass homogenate before and after drying at $70^{\circ} \mathrm{C}$ in a vacuum oven. Fat content was determined by the method of Folch et al. (1957) and converted to energy as fat using the coefficient of $39.2 \mathrm{~kJ} / \mathrm{g}$. Protein content was determined as described by Brooks et al. (1995) and converted to energy as protein by using the value of $23.5 \mathrm{~kJ} / \mathrm{g}$. Protein and fat gain was calculated as the difference between the protein and fat content at the end of the experimental period and the respective content of the rats killed at the beginning of the experiment.

\section{Circulating substrate and hormone serum concentrations}

The blood samples were centrifuged at $2000 \boldsymbol{g}_{\text {av }}$ for $10 \mathrm{~min}$. The serum was removed and stored at $-20^{\circ} \mathrm{C}$ until used for the determination of free $\mathrm{T}_{3}$, insulin, leptin, glucose, and non-esterified fatty acids (NEFA) concentration. Serum free $T_{3}$, insulin, and leptin concentrations were measured using radioimmunoassay kits (ICN Pharmaceuticals, Diagnostic Division, New York, NY, USA for free $\mathrm{T}_{3}$, and Linco Research, Inc., St Charles, MO, USA for insulin and leptin). Each hormone was measured in a single assay to remove inter-assay variations. Serum NEFA and glucose were measured by the colorimetric enzymic method using commercial kits (Roche Diagnostics, Mannheim, Germany for NEFA, and Pokler Italia, Genova, Italy for glucose).

\section{Preparation of homogenates and isolated mitochondria}

After removal, the livers were finely minced and washed in a medium containing $220 \mathrm{~mm}$-mannitol, $70 \mathrm{~mm}-$ sucrose, $20 \mathrm{~mm}-\mathrm{N}^{\prime}$-(2-hydroxyethyl)piperazine-N-2-ethanesulfonic acid (HEPES) (pH 7.4), 1 mM-EDTA, and 0.1\% (w/v) fatty-acid-free bovine serum albumin (BSA). Tissue fragments were homogenised with the above medium $(1: 4, w / v)$ in a Potter Elvehjem homogeniser (Heidolph, Kelheim, Germany) set at $500 \mathrm{rpm}$ (4 strokes $/ \mathrm{min}$ ). Samples of homogenate were used for respiration measurements. The use of homogenate allows the linking of mitochondrial oxidative capacities with the effective mitochondrial protein mass. The remainder of the homogenate was centrifuged at $1000 g_{\text {av }}$ for $10 \mathrm{~min}$ and the resulting supernatant fraction was again centrifuged 
at $3000 g_{\text {av }}$ for $10 \mathrm{~min}$. The mitochondrial pellet was washed twice and finally re-suspended in a medium containing $80 \mathrm{~mm}-\mathrm{KCl}, 50 \mathrm{~mm}-\mathrm{HEPES}(\mathrm{pH} 7 \cdot 0$ ), $5 \mathrm{~mm}-$ $\mathrm{KH}_{2} \mathrm{PO}_{4}$, and $0 \cdot 1 \%(\mathrm{w} / \mathrm{v})$ fatty-acid-free BSA. The protein content of the mitochondrial suspension was determined by the method of Hartree (1972) using BSA as the protein standard. Isolated mitochondria were then used for the determination of respiratory parameters and $\alpha$-glycerophosphate dehydrogenase ( $\alpha$-GPDH; EC $1 \cdot 1 \cdot 1 \cdot 8$ ) activity by the method described by Lee \& Lardy (1965).

Hind-leg muscles were freed of excess fat and connective tissue, finely minced and washed in a medium containing $100 \mathrm{~mm}-\mathrm{KCl}, \quad 50 \mathrm{~mm}$-tri(hydroxymethyl)-aminomethane (pH 7.5), $5 \mathrm{~mm}-\mathrm{MgCl}_{2}, 1 \mathrm{~mm}$-EDTA, 5 mM-EGTA, and $0.1 \%(\mathrm{w} / \mathrm{v})$ fatty-acid-free BSA. Tissue fragments were treated with protease nagarse (EC 3.4.21.62; $1 \mathrm{mg} / \mathrm{g}$ tissue) for $5 \mathrm{~min}$, washed, homogenised with the above medium $(1: 8, \mathrm{w} / \mathrm{v})$ in a Potter Elvehjem homogeniser set at $500 \mathrm{rpm}$ (4 strokes $/ \mathrm{min})$ and filtered. Samples of the homogenate were then used for the determination of mitochondrial respiration as well as for the preparation of isolated mitochondria. To this end, the homogenate was centrifuged at $500 g_{\mathrm{av}}$ for $10 \mathrm{~min}$ and the supernatant fraction was centrifuged at $3000 \mathrm{~g}_{\mathrm{av}}$ for $10 \mathrm{~min}$. The resulting pellet containing mitochondria was washed twice, and finally re-suspended in a suspension medium containing $250 \mathrm{~mm}$-sucrose, $50 \mathrm{~mm}$-tri(hydroxymethyl)-aminomethane (pH 7.5), and $0.1 \%$ fatty-acid-free BSA. The protein content of the mitochondrial suspension was determined by the method of Hartree (1972) using BSA as the protein standard. Isolated mitochondria were then used for the determination of respiratory parameters and $\alpha-G P D H$ activity.

\section{Polarographic measurement of respiration}

Mitochondrial $\mathrm{O}_{2}$ consumption was estimated by a Clarktype electrode (Yellow Springs Instruments, Yellow Springs, OH, USA), maintained in a water-jacketed chamber at $30^{\circ} \mathrm{C}$. Hepatic mitochondria $(0.9 \mathrm{mg}$ protein $)$ or samples of the liver homogenate were incubated in a medium $(3 \mathrm{ml})$ containing $80 \mathrm{~mm}-\mathrm{KCl}, 50 \mathrm{~mm}-\mathrm{HEPES}, 1 \mathrm{mM}-\mathrm{EGTA}$, $5 \mathrm{mM}-\mathrm{KH}_{2} \mathrm{PO}_{4}(\mathrm{pH} 7 \cdot 0)$, and $0.1 \%(\mathrm{w} / \mathrm{v})$ fatty-acid-free BSA. Skeletal muscle mitochondria $(0.3 \mathrm{mg}$ protein) or samples of the muscle homogenate were incubated in a medium $(3 \mathrm{ml})$ containing $30 \mathrm{mM}-\mathrm{KCl}, 6 \mathrm{mM}^{-\mathrm{MgCl}_{2}}$, $75 \mathrm{~mm}$-sucrose, $1 \mathrm{~mm}$-EDTA, $20 \mathrm{mM}-\mathrm{KH}_{2} \mathrm{PO}_{4}$ (pH 7.0), and $0.1 \%(\mathrm{w} / \mathrm{v})$ fatty-acid-free BSA.

The substrates used for both liver and muscle respiration were $10 \mathrm{mM}$-succinate $+3.75 \mu \mathrm{M}$-rotenone, $10 \mathrm{mM}$ glutamate $+2.5 \mathrm{~mm}$-malate or $40 \mu \mathrm{M}$-palmitoyl-carnitine $+2.5 \mathrm{~mm}$-malate. State 3 measurements were performed in the presence of $0.6 \mathrm{~mm}$-ADP. State 4 respiration was measured in the presence of oligomycin $(4 \mu \mathrm{g} / \mathrm{ml})$ in the homogenates or in the absence of ADP in isolated mitochondria. The ratio between state 3 and 4, called the respiratory control ratio, was calculated according to Estabrook (1967).

\section{Statistical analysis}

Data are given as means with their standard errors for eight different rats per group. Statistical analysis was performed by the two-tailed Student's $t$ test. Regression analyses were also performed. Probability values less than 0.05 were considered to indicate a significant difference. All analyses were performed using GraphPad Prism (GraphPad Software, San Diego, CA, USA).

\section{Materials}

ADP, malate, glutamate, succinate, rotenone, palmitoylcarnitine, $\alpha$-glycerophosphate, nagarse, iodonitrotetrazolium violet, phenazine methosulfate, and oligomycin were purchased from Sigma Chemical Co., St Louis, MO, USA. All other reagents were of the highest purity commercially available.

\section{Results}

The changes in body composition and energy content are given in Table 1. The percentage of body fat and body energy content significantly increased in the rats fed the high-fat diet compared with the rats fed the low-fat diet.

Table 2 provides the changes in energy balance, partitioning, and efficiency over the experimental period. The rats fed the high-fat diet exhibited significantly higher ME and fat intakes together with body-energy and fat gain. Both energy expenditure and net energy expenditure (the value obtained for energy expenditure excluding the

Table 1. Body weight and composition in rats at baseline and in rats fed a low-fat or a high-fat diet $†$ (Mean values with their standard errors for eight rats per group)

\begin{tabular}{|c|c|c|c|c|c|c|c|}
\hline & & & \multicolumn{4}{|c|}{ Diet } & \multirow[b]{3}{*}{ Difference (\%)† } \\
\hline & \multicolumn{2}{|c|}{ Baseline } & \multicolumn{2}{|c|}{ Low-fat } & \multicolumn{2}{|c|}{ High-fat } & \\
\hline & Mean & SE & Mean & SE & Mean & SE & \\
\hline Body weight (g) & 400 & 1 & 444 & 4 & 454 & 5 & $2 \cdot 2$ \\
\hline Body water (\%) & $69 \cdot 1$ & 0.1 & $64 \cdot 7$ & 0.5 & $63 \cdot 3$ & $1 \cdot 2$ & $-2 \cdot 3$ \\
\hline Body fat (\%) & $7 \cdot 4$ & 0.1 & $11 \cdot 1$ & 0.6 & $14 \cdot 1^{*}$ & $1 \cdot 1$ & 27 \\
\hline Body protein (\%) & $17 \cdot 5$ & 0.2 & $17 \cdot 9$ & 0.4 & $16 \cdot 8$ & 0.6 & -6 \\
\hline Body energy $(\mathrm{kJ} / \mathrm{g})$ & $7 \cdot 0$ & 0.1 & 8.5 & 0.2 & $9 \cdot 5^{\star}$ & 0.4 & $11 \cdot 8$ \\
\hline
\end{tabular}

* Mean value was significantly different to that for rats fed the low-fat diet $(P<0.05)$.

†For details of diets and procedures, see lossa et al. (2002) and p. 954.

$\ddagger$ Percentage difference values refer to the high-fat diet compared with the low-fat diet. 
Table 2. Energy balance, partitioning of metabolisable energy (ME) intake, and efficiency in rats fed a low-fat or a high-fat diet† (Mean values with their standard errors for eight rats per group)

\begin{tabular}{|c|c|c|c|c|c|}
\hline \multirow{2}{*}{ Diet. . } & \multicolumn{2}{|c|}{ Low-fat } & \multicolumn{2}{|c|}{ High-fat } & \multirow{2}{*}{$\begin{array}{l}\text { Difference } \\
\quad(\%) \ddagger\end{array}$} \\
\hline & Mean & SE & Mean & SE & \\
\hline ME intake (kJ) & 4405 & 278 & $6037^{\star}$ & 383 & 37 \\
\hline Fat intake (kJ) & 467 & 29 & $3019^{*}$ & 191 & 546 \\
\hline $\begin{array}{l}\text { Body-energy } \\
\text { gain }(\mathrm{kJ})\end{array}$ & 974 & 34 & $1513^{*}$ & 241 & 55 \\
\hline Protein gain $(\mathrm{kJ})$ & 193 & 35 & 139 & 15 & -28 \\
\hline Fat gain $(\mathrm{kJ})$ & 789 & 61 & $1354^{*}$ & 140 & 72 \\
\hline $\begin{array}{l}\text { Energy } \\
\quad \text { expenditure (kJ) }\end{array}$ & 3431 & 255 & $4524^{*}$ & 259 & 32 \\
\hline $\begin{array}{l}\text { Cost of } \\
\text { storage (kJ) }\end{array}$ & 526 & 55 & $382^{*}$ & 37 & -27 \\
\hline NEE $(k J)$ & 2905 & 190 & $4142^{\star}$ & 169 & 42 \\
\hline $\begin{array}{l}\text { NEE/ME } \\
\times 100(\%)\end{array}$ & $66 \cdot 0$ & 0.5 & $69 \cdot 5$ & 3.6 & 4.5 \\
\hline $\begin{array}{l}\text { Fat gain/ME } \\
\quad \times 100(\%)\end{array}$ & $18 \cdot 5$ & 0.6 & $22 \cdot 4^{\star}$ & 1.5 & 21 \\
\hline $\begin{array}{l}\text { Fat gain/fat } \\
\text { intake } \times 100(\%)\end{array}$ & 174 & 22 & $43 \cdot 2^{\star}$ & $8 \cdot 3$ & -75 \\
\hline $\begin{array}{l}\text { Energetic } \\
\quad \text { efficiency (\%) }\end{array}$ & $22 \cdot 0$ & 0.8 & $25 \cdot 0^{\star}$ & $1 \cdot 1$ & 14 \\
\hline
\end{tabular}

* Mean value was significantly different to that for rats fed the low-fat diet $(P<0.05)$.

$\dagger$ Values refer to the whole period of the diet treatment (2 weeks). For details of diets and procedures, see lossa et al. (2002) and p. 954.

$\ddagger$ Percentage difference values refer to the high-fat diet compared with the low-fat diet.

NEE, net energy expenditure (the difference between energy expenditure and cost of storage).

total cost of storage) significantly increased in the rats fed the high-fat diet compared with the rats fed the low-fat diet. When net energy expenditure was expressed as the percentage of $\mathrm{ME}$ intake, no significant variation was found in the rats fed the high-fat diet. As for fat partitioning, Table 2 also shows that the percentage of ME intake stored as fat was significantly higher in the rats fed the high-fat diet, while the percentage of fat intake stored as fat decreased in the rats fed the highfat diet compared with the rats fed the low-fat diet. Finally, gross energetic efficiency significantly increased in the rats fed the high-fat diet compared with the rats fed the low-fat diet.

As for serum leptin and free $\mathrm{T}_{3}$ levels, no significant variation was found in serum free $\mathrm{T}_{3}$, while serum leptin levels significantly increased in the rats fed the high-fat diet compared with the rats fed the low-fat diet (Fig. 1 (A)). Fig. 1 (B) shows the correlation between leptin and body fat in the rats fed the low- or the high-fat diet. Serum leptin levels were positively correlated with the percentage of body fat in both groups of rats, but the slopes of the regression lines were significantly different. A significant inverse correlation was found between serum leptin levels and ME intake in the rats fed the low-fat diet, whereas a direct correlation occurred between these parameters in the rats fed the high-fat diet (Fig. 1 (C)). The serum levels of NEFA, glucose, and insulin as well as insulin:glucose are presented in Table 3. Serum NEFA, glucose, and insulin levels were slightly elevated in the rats fed the high-fat diet compared with the rats fed the low-fat
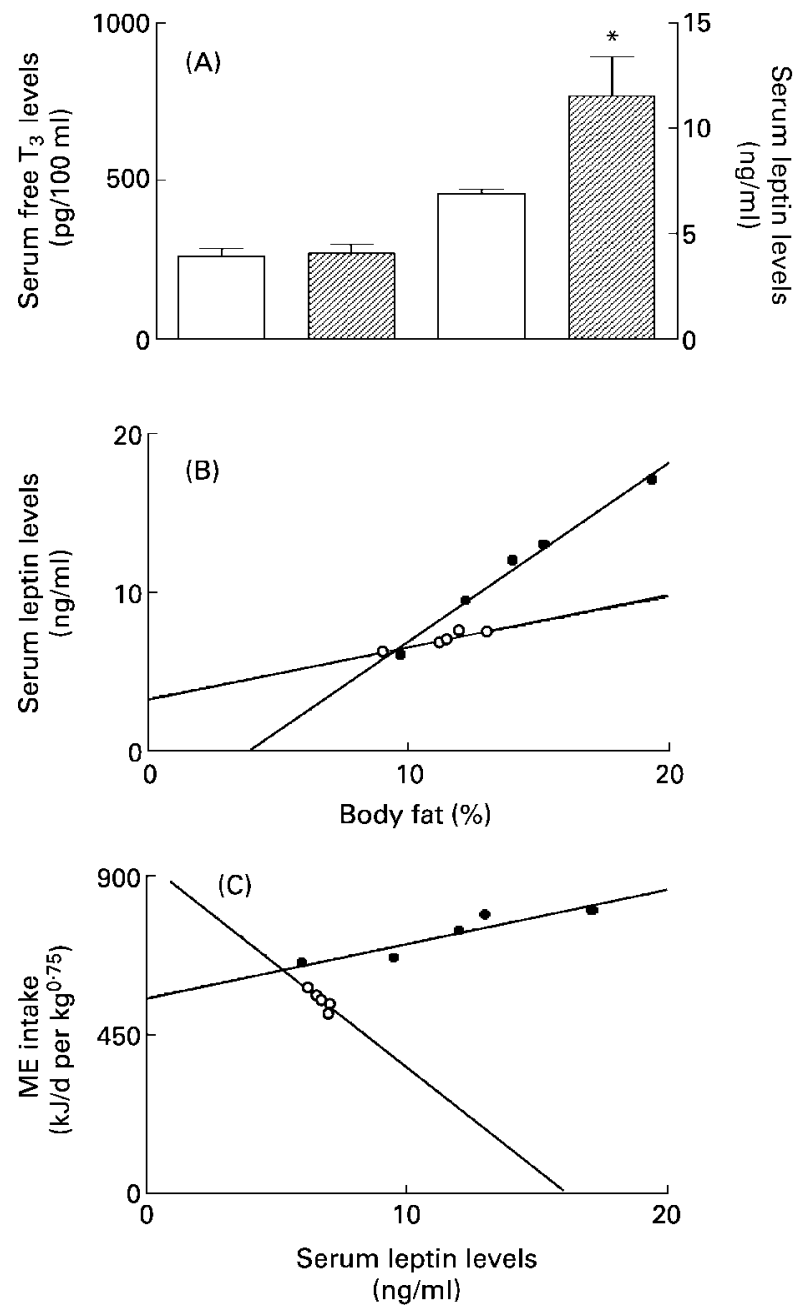

Fig. 1. (A), Serum free triiodothyronine $\left(T_{3}\right)$ and leptin levels in rats fed a low-fat $(\square)$ or a high-fat (ש) diet. Values are means, with their standard errors shown by vertical bars (five rats per group). * Mean value for leptin level was significantly different from that for the lowfat diet $(P<0 \cdot 05)$. (B), Correlation between serum leptin levels and percentage of body fat in rats fed a low-fat (०) or a high-fat $(\bullet)$ diet. Each point represents an individual value. The association for the low-fat diet was $r^{2} 0.871(P=0.02)$; that for the high-fat diet was $r^{2}$ $0.987(P=0.0006)$. (C), Correlation between daily metabolisable energy (ME) intake and serum leptin levels in rats fed a low-fat (O) or a high-fat $(\bullet)$ diet. Each point represents an individual value. The association for the low-fat diet was $r^{2} 0.934(P=0.007)$; that for the high-fat diet was $r^{2} 0.855(P=0.024)$.

diet. However, statistical analysis indicated no significant difference between the two groups of rats. In addition, no change was found in insulin:glucose.

Mitochondrial state 3 and 4 respiratory capacities were measured in the liver and skeletal muscle homogenates to assess the metabolic activity of the whole tissue stimulated by NAD-and FAD-linked substrates. As for the liver, whatever was the substrate, mitochondrial capacities significantly increased in the liver homogenates from the rats fed the high-fat diet compared with the rats fed the low-fat diet (Table 4). In addition, a significant inverse correlation was found between the percentage of fat intake stored as body fat and hepatic palmitoyl-carnitine-supported 
Table 3. Serum non-esterified fatty acids (NEFA), glucose and insulin levels and serum insulin:glucose in rats fed a low-fat or a high-fat diet*

(Mean values with their standard errors for eight rats per group)

\begin{tabular}{|c|c|c|c|c|c|}
\hline \multirow{2}{*}{ Diet... } & \multicolumn{2}{|c|}{ Low-fat } & \multicolumn{2}{|c|}{ High-fat } & \multirow{2}{*}{$\begin{array}{l}\text { Difference } \\
(\%) \dagger\end{array}$} \\
\hline & Mean & SE & Mean & SE & \\
\hline NEFA $(\mathrm{mmol} / \mathrm{l})$ & 0.215 & 0.017 & 0.240 & 0.019 & 12 \\
\hline $\begin{array}{l}\text { Glucose } \\
\text { (mg/100 ml) }\end{array}$ & 168 & 9 & 180 & 9 & 7 \\
\hline Insulin (ng/ml) & $2 \cdot 89$ & $0 \cdot 1$ & 3.11 & 0.2 & 8 \\
\hline $\begin{array}{l}\text { Insulin:glucose } \\
\left(\times 10^{-6}\right)\end{array}$ & 1.72 & 0.1 & 1.73 & 0.1 & 0.6 \\
\hline
\end{tabular}

* For details of diets and procedures, see lossa et al. (2002) and p. 954.

†Percentage difference values refer to the high-fat diet compared with the low-fat diet.

respiration (Fig. 2). On the contrary, no variation was found in skeletal muscle homogenate respiration between the rats fed the low-fat diet and the rats fed the high-fat diet (Table 4).

State 3 and 4 respiratory capacities were also measured in the isolated liver and skeletal muscle mitochondria to take into account the changes in specific respiratory capacity due to high-fat feeding. The respiratory control ratio values indicated that isolated mitochondria were well coupled (Table 5). Whatever substrate was used, both state 3 and 4 respiratory capacities significantly decreased in the rats fed the high-fat diet compared with the rats fed the low-fat diet (Table 5). Liver and skeletal muscle mitochondrial $\alpha$-GPDH specific activity was not affected by diet treatment (Table 5).

\section{Discussion}

The results of the present study show that high-fat feeding in adult rats induces not only an increase in fat storage but also impairment in liver and muscle mitochondrial respiratory capacities.
The evaluation of the changes in energy balance shows that adult rats are much more prone to become obese compared with young rats, when fed diets rich in fat. In fact, the adults rats fed the high-fat diet for 2 weeks exhibited an increase in ME intake and in the percentage of ME intake stored as fat (Table 2), as well as a higher body fat content (Table 1). The present results are different from those previously obtained in post-weaning rats fed a high-fat diet for 2 weeks. Mollica et al. (1999) found increased ME intake, but no change in body fat content between low-fat- or high-fat-fed rats, due to a decrease in the percentage of ME intake stored as fat. The difference can be attributed to the fact that in post-weaning rats, the energy ingested in excess is dissipated through an adaptive increase in energy expenditure, as indicated by the increase in the percentage of ME intake utilised for body energy maintenance and by the decrease in energetic efficiency (Iossa et al. 1997). Since the efficiency of nutrient utilisation is higher for fat than for carbohydrate or protein (Jéquier, 2002), high-fat feeding tends to increase rather than decrease energetic efficiency. It follows that only the presence of adaptive thermogenesis could justify a decrease in metabolic efficiency during a dietetic regimen rich in fat. The presence of diet-induced thermogenesis to limit excess energy storage in young rats overeating palatable food (rich in fat) has been previously suggested by the classic studies of Rothwell \& Stock (1982). On the other hand, the present results show that when net energy expenditure, which represents the cost of body energy maintenance, was expressed as a percentage of ME intake, the values obtained did not significantly change between rats fed a low- or a high-fat diet. These results suggest that in adult rats regulatory mechanisms useful to counteract obesity development are absent and, therefore, the excess ingested energy will contribute to enlarge fat stores. In agreement, energetic efficiency increased in the adult rats fed the high-fat diet (Table 2). However, an interesting observation is that the ability to utilise fat as

Table 4. Mitochondrial respiration ( $\mathrm{ng}$ atoms $\mathrm{O} / \mathrm{min} \times \mathrm{g}$ wet tissue) in liver and skeletal muscle homogenates from rats fed a low-fat or a high-fat diet

(Mean values with their standard errors for eight rats per group)

\begin{tabular}{|c|c|c|c|c|c|c|}
\hline \multirow{2}{*}{ Diet... } & & \multicolumn{2}{|c|}{ Low-fat } & \multicolumn{2}{|c|}{ High-fat } & \multirow[b]{2}{*}{ Difference (\%)‡ } \\
\hline & & Mean & SE & Mean & SE & \\
\hline \multicolumn{7}{|l|}{ Liver } \\
\hline \multirow{2}{*}{ Glutamate } & State 3 & 5207 & 241 & $6172^{*}$ & 360 & 18 \\
\hline & State 4 & 251 & 20 & $315^{*}$ & 21 & 25 \\
\hline \multirow[t]{2}{*}{ Palmitoyl-carnitine } & State 3 & 4650 & 133 & $6034^{*}$ & 260 & 30 \\
\hline & State 4 & 280 & 24 & $340^{*}$ & 14 & 21 \\
\hline \multirow[t]{2}{*}{ Succinate } & State 3 & 9218 & 393 & $11246^{\star}$ & 327 & 22 \\
\hline & State 4 & 985 & 51 & $1179^{*}$ & 73 & 20 \\
\hline \multicolumn{7}{|l|}{ Skeletal muscle } \\
\hline \multirow{2}{*}{ Glutamate } & State 3 & 3446 & 79 & 3796 & 224 & 10 \\
\hline & State 4 & 171 & 37 & 168 & 35 & -2 \\
\hline \multirow[t]{2}{*}{ Palmitoyl-carnitine } & State 3 & 2160 & 222 & 2304 & 211 & 7 \\
\hline & State 4 & 122 & 20 & 116 & 16 & -5 \\
\hline \multirow[t]{2}{*}{ Succinate } & State 3 & 5729 & 460 & 5413 & 584 & -6 \\
\hline & State 4 & 945 & 111 & 832 & 66 & -12 \\
\hline
\end{tabular}

* Mean value was significantly different to that for rats fed the low-fat diet $(P<0.05)$.

$\dagger$ For details of diets and procedures, see lossa et al. (2002) and p. 955.

$\ddagger$ Percentage difference values refer to the high-fat diet compared with the low-fat diet. 


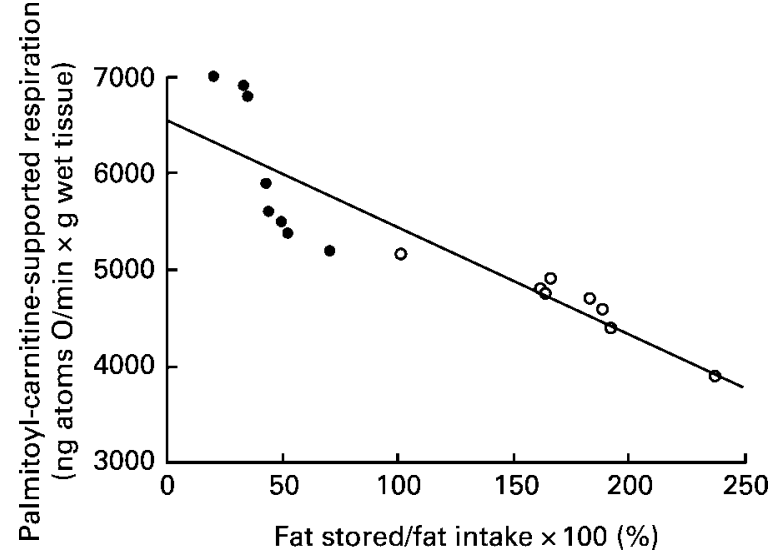

Fig. 2. Correlation between hepatic palmitoyl-carnitine-supported respiration and percentage of fat intake stored as body fat in rats fed a low-fat (o) or a high-fat (•) diet. Each point represents an individual value $\left(r^{2} 0.7828 ; P<0.0001\right)$.

a metabolic fuel is elevated in adult rats fed a high-fat diet. In fact, the present results also show that when fat gain was expressed as a percentage of fat intake, significantly lower values were obtained for the rats fed the high-fat diet (Table 2). In addition, a negative correlation was found between the percentage of fat intake stored as body fat and palmitoyl-carnitine-supported respiration only in the liver (Fig. 2). It follows that, in adult rats, changes in fat storage seem to be related to changes in fat oxidation in the liver but not in skeletal muscle. On the other hand, when the dietary regimen was applied to 25-d-old rats (Iossa et al. 2002), a negative correlation between the percentage of fat intake stored as body fat and skeletal muscle palmitoyl-carnitine-supported respiration was found. Therefore, the mechanisms of regulation of lipid oxidation in skeletal muscle in response to increased dietary intake are switched on in young rats, resistant to obesity, while they are not activated in adult rats, which develop obesity.

To gain insight into the hormonal modification induced by high-fat feeding in 90-d-old rats, the serum levels of free $\mathrm{T}_{3}$, insulin, and leptin, all involved in the regulation on nutrient metabolism, were measured (Muller \& Seitz, 1984; Friedman, 2002; Porte et al. 2002). High-fat feeding did not affect the serum free $\mathrm{T}_{3}$ levels in adult rats (Fig. 1 (A)). A different finding was obtained in post-weaning rats (Iossa et al. 1995), where higher serum free $\mathrm{T}_{3}$ levels were found in the rats fed the high-fat diet compared with the rats fed the low-fat diet, associated with increased hepatic mitochondrial $\alpha$-GPDH activity, an enzyme that is induced by $\mathrm{T}_{3}$ (Bobyleva et al. 2000). These results allowed Iossa et al. (1995) to suggest an involvement of $\mathrm{T}_{3}$ in adaptive responses, which occur in young rats fed a high-fat diet. In fact, it is known that the $\alpha-G P D H$ enzyme is rate-limiting for the $\alpha$-glycerophosphate shuttle (Tyzbir et al. 1981) and reportedly is involved in processes that could decrease metabolic efficiency (Lardy et al. 1995). In the present work, in agreement with the finding that $\mathrm{T}_{3}$ levels did not change in the 90-d-old rats fed the high-fat diet, no changes were found in $\alpha-G P D H$ activities both in the liver- and skeletal-muscle-isolated mitochondria (Table 5).

Since serum insulin and glucose levels as well as insulin: glucose did not significantly change between the two

Table 5. Respiration (ng atoms $\mathrm{O} / \mathrm{min} \times \mathrm{mg}$ protein) in liver and skeletal muscle mitochondria from rats fed a low-fat or a high-fat diet $†$ (Mean values with their standard errors for eight rats per group)

\begin{tabular}{|c|c|c|c|c|c|c|}
\hline \multirow{2}{*}{ Diet... } & & \multicolumn{2}{|c|}{ Low-fat } & \multicolumn{2}{|c|}{ High-fat } & \multirow[b]{2}{*}{ Difference (\%)‡ } \\
\hline & & Mean & SE & Mean & SE & \\
\hline \multicolumn{7}{|l|}{ Liver } \\
\hline \multirow[t]{3}{*}{ Glutamate } & State 3 & 84 & 7 & $62^{*}$ & 4 & -26 \\
\hline & State 4 & 8.4 & 0.4 & $6 \cdot 7^{\star}$ & 0.3 & -20 \\
\hline & $\mathrm{RCR}$ & $10 \cdot 0$ & 0.7 & $9 \cdot 2$ & 0.4 & -8 \\
\hline \multirow[t]{2}{*}{ Palmitoyl-carnitine } & State 3 & 77 & 4 & $59^{*}$ & 2 & -23 \\
\hline & RCR & 6.7 & 0.3 & 6.6 & 0.4 & -0.01 \\
\hline \multirow[t]{3}{*}{ Succinate } & State 3 & 152 & 9 & $108^{\star}$ & 3 & -29 \\
\hline & State 4 & 23 & 0.7 & $18^{*}$ & 1 & -22 \\
\hline & $\mathrm{RCR}$ & $6 \cdot 6$ & 0.3 & $6 \cdot 0$ & 0.3 & -9 \\
\hline$\alpha$-GPDH activity (nmol/min $\times$ mg protein) & & 10 & 1 & 9 & 2 & -0.1 \\
\hline \multicolumn{7}{|l|}{ Skeletal muscle } \\
\hline \multirow[t]{2}{*}{ Glutamate } & State 3 & 1039 & 75 & $756^{\star}$ & 76 & -27 \\
\hline & State 4 & 64 & 4 & $48^{*}$ & 3 & -25 \\
\hline \multirow[t]{3}{*}{ Palmitoyl-carnitine } & State 3 & 382 & 21 & $257^{*}$ & 19 & -33 \\
\hline & State 4 & 60 & 5 & $44^{*}$ & 4 & -27 \\
\hline & RCR & 6.4 & 0.3 & $5 \cdot 8$ & $1 \cdot 0$ & -9 \\
\hline \multirow[t]{3}{*}{ Succinate } & State 3 & 1037 & 36 & $842^{*}$ & 55 & -19 \\
\hline & State 4 & 173 & 11 & $139^{*}$ & 9 & -20 \\
\hline & RCR & $6 \cdot 0$ & $1 \cdot 0$ & $6 \cdot 1$ & 0.3 & 2 \\
\hline$\alpha$-GPDH activity $(\mathrm{nmol} / \mathrm{min} \times \mathrm{mg}$ protein) & & 85 & 6 & 95 & 11 & 12 \\
\hline
\end{tabular}

$\mathrm{RCR}$, respiratory control ratio; $\alpha$-GPDH, $\alpha$-glycerophosphate dehydrogenase.

* Mean value was significantly different to that for rats fed the low-fat diet $(P<0.05)$.

†For details of diets and procedures, see lossa et al. (2002) and p. 955.

$\ddagger$ Percentage difference values refer to the high-fat diet compared with the low-fat diet. 
groups of rats (Table 3), the feeding of a high-fat diet for 2 weeks is characterised by normal insulin sensitivity. This result is not in agreement with previous studies, where a high-fat diet induced insulin resistance (Spicer, 2002; Woods et al. 2003). However, in these studies, the highfat-diet treatment lasted for more than 2 weeks. It seems that the length of the high-fat feeding is an important factor for the development of insulin resistance.

As for serum leptin levels, a significant increase was found in the adult rats fed the high-fat diet compared with the control rats (Fig. 1 (A)) in agreement with the greater body fat content exhibited by these rats. On the other hand, Mollica et al. (1999) found no variations in leptin levels and body fat content in post-weaning rats fed a high-fat diet. Also, Iossa et al. (1999b) showed increased serum leptin levels and body fat content in middle-aged rats ( $180 \mathrm{~d}$ of age) fed a low-fat diet. It can be suggested that high-fat feeding could anticipate the effect of ageing on body-fat gain and serum leptin levels. A significant positive correlation between serum leptin levels and body fat mass was always found (Fig. 1 (B)), in agreement with the observation that leptin circulates in proportion to body mass in rodents (Friedman, 2002). Interestingly the slope of the regression line obtained for the adult rats fed the high-fat diet was significantly higher than that found in the control rats. This result suggests that the increase in leptin levels found in the adult rats fed the high-fat diet is due to other factors beyond increased body fat stores. It has been shown that the sympathetic nervous system inhibits $o b$ gene transcription in adipose tissue through $\beta_{3}$ adrenergic receptors ( $\mathrm{Li}$ et al. 1997; Evans et al. 1999). In addition, it has been found that high-fat feeding adversely affects adipocyte adrenergic receptor expression and function (Collins et al. 1997). It can be speculated that the higher leptin levels, found in the adult rats fed the high-fat diet, could be due not only to higher body fat mass, but also to defective adrenergic control of adipocyte function. Consistent with the inhibitory action of leptin on food intake (Schwartz et al. 1996), a significant inverse correlation between serum leptin levels and ME intake was found in the rats fed the low-fat diet. On the other hand, a significant positive correlation was found between these two parameters in the rats fed the high-fat diet (Fig. 1 (C)). This finding suggests that high-fat feeding in 90-d-old rats eliminates the susceptibility to the anorexic effect of leptin. It should be noted that a reduction in the anorexic effect of leptin has been reported in old rats (Scarpace et al. 2000). In addition, in a previous study, it was found that from $90 \mathrm{~d}$ of age onwards a progressive reduction in the responsiveness of the rat to the leptin signal takes place (Iossa et al. $1999 b)$. Therefore, it can be suggested that a nutritional factor, such as a high fat level in the diet, can induce the reduction in responsiveness to leptin, a phenomenon typical of ageing. This suggestion is in agreement with the observation that the chronic administration of a high-fat diet to rats results in a reduced uptake of leptin into the brain and an impaired intracellular signal transduction (El-Haschimi et al. 2000). Since it has been shown that the capacity to resist obesity development tends to decrease with age (Barzilai \& Rossetti, 1995; Iossa et al. 1999b), it is conceivable that high-fat feeding in adult rats anticipates the fall in physiological mechanisms that allow the maintenance of body weight.

The present results also showed that adult rats fed a high-fat diet exhibited a significant decrease in specific respiratory capacities whatever substrate was used for both liver- and skeletal-muscle-isolated mitochondria (Table 5). On the other hand, higher skeletal muscle mitochondrialspecific respiratory capacities have previously been found in post-weaning rats fed a high-fat diet compared with rats fed a low-fat diet (Iossa et al. 2002), but no diet-related difference was found in the liver-specific respiratory capacity of mitochondria isolated from post-pubertal rats (Iossa et al. 1999a). Taking into account that a general decline in mitochondrial oxidative capacities is associated with the ageing process (Ames et al. 1995), it can be suggested that high-fat feeding causes an early onset of mitochondrial decay in adult rats. However, in the present study the impairment in oxidative capacities in isolated mitochondria did not affect whole-tissue oxidative function. In fact, no variation was found in the mitochondrial oxidative capacity of skeletal muscle homogenates and a significant increase in liver homogenates was found. It can be speculated that an increase in the mass of muscle and liver mitochondria compensates for the reduced oxidative capacities found in isolated mitochondria. This suggestion is consistent with the recovered mitochondrial protein contents from the liver and skeletal muscle, which were significantly higher in the rats fed the highfat diet (data not shown). In addition, Nemeth et al. (1992) have found increases in the oxidative enzymes of the tricarboxylic acid cycle and in $\beta$-hydroxyacyl-CoA dehydrogenase, an enzyme for fatty acid oxidation, measured in skeletal muscle homogenate from adult rats fed a high-fat diet.

Taken together, the present results demonstrate that adult rats have a lower capacity to resist diet-induced obesity, probably due to the failure of adaptive mechanisms, which counteract obesity in young rats. In addition, the present study found that a nutritional factor, such as a high level of fat in the diet, induces an impairment of mitochondrial respiratory capacities, even if, probably, compensated by an increase in mitochondrial protein mass. The overall conclusion of the present study is that high-fat feeding in 90-d-old rats induces an early onset of obesity and impairment in isolated mitochondrial oxidative capacity, both phenomena typical of ageing.

\section{Acknowledgement}

This work was supported by grant MIUR-COFIN 2002.

\section{References}

Ames BN, Shigenaga MK \& Hagen TN (1995) Mitochondrial decay in aging. Biochim Biophys Acta 1271, 165-170.

Barzilai N \& Rossetti L (1995) Relationship between changes in body composition and insulin responsiveness in models of the aging rat. Am J Physiol 269, E591-E597.

Bobyleva V, Pazienza L, Muscatello U, Kneer N \& Lardy H (2000) Short-term hypothermia activates hepatic mitochondria 
sn-glycerol 3-phosphate dehydrogenase and thermogenic systems. Arch Biochem Biophys 380, 367-372.

Brooks SPJ, Lampi BJ, Sarwar G \& Botting HG (1995) A comparison of methods for determining total body protein. Anal Biochem 226, 26-30.

Collins S, Daniel KW, Petro AN \& Surwit RS (1997) Strain-specific response to $\beta 3$-adrenergic receptor agonist treatment of diet-induced obesity in mice. Endocrinology 138, 405-413.

Danforth E \& Burger AG (1989) The impact on nutrition on thyroid hormone physiology and action. Annu Rev Nutr 9, 201-227.

El-Haschimi K, Pierroz DD, Hileman SM, Bjorbaek C \& Flier JS (2000) Two defects contribute to hypothalamic leptin resistance in mice with diet-induced obesity. $J$ Clin Invest 105, 1827-1832.

Estabrook RW (1967) Mitochondrial respiratory control and the polarographic measurement of ADP:O ratios. Methods Enzymol 10, $41-47$.

Evans BA, Agar L \& Summers RJ (1999) The role of the sympathetic nervous system in the regulation of leptin synthesis in C57BL/6 mice. FEBS Lett 444, 149-154.

Folch J, Lees M \& Sloane-Stanley GH (1957) A simple method for the isolation and purification of total lipides from animal tissues. J Biol Chem 226, 497-510.

Freake HG \& Oppenheimer JH (1995) Thermogenesis and thyroid function. Annu Rev Nutr 15, 263-291.

Friedman JM (2002) The function of leptin in nutrition, weight, and physiology. Nutr Rev 60, S1-S14.

Hartree EF (1972) Determination of protein: a modification of the Lowry method that gives a linear photometric response. Anal Biochem 48, 422-427.

Hill JO, Melanson EL \& Wyatt HT (2000) Dietary fat intake and regulation of energy balance: implication for obesity. $J$ Nutr 130, 284S-288S.

Iossa S, Lionetti L, Mollica MP, Barletta A \& Liverini G (1999a) Fat balance and hepatic mitochondrial function in response to fat feeding in mature rats. Int J Obes Relat Metab Disord 23, $1122-1128$

Iossa S, Lionetti L, Mollica MP, Barletta A \& Liverini G (1999b) Energy intake and utilization vary during development in rats. J Nutr 129, 1593-1596.

Iossa S, Lionetti L, Mollica MP, Crescenzo R, Botta M \& Liverini G (2001) Mitochondrial respiration and triiodothyronine concentration in liver from postpubertal and adult rats. Horm Metab Res 33, 1-5.

Iossa S, Mollica MP, Lionetti L, Barletta A \& Liverini G (1995) Hepatic mitochondrial respiration and transport of reducing equivalents in rats fed an energy dense diet. Int $J$ Obes Relat Metab Disord 19, 539-543.

Iossa S, Mollica MP, Lionetti L, Barletta A \& Liverini G (1997) Energy balance and liver respiratory activity in rats fed on an energy-dense diet. Br J Nutr 77, 99-105.

Iossa S, Mollica MP, Lionetti L, Crescenzo R, Botta M \& Liverini G (2002) Skeletal muscle oxidative capacity in rats fed high-fat diet. Int J Obes Relat Metab Disord 26, 65-72.

Jéquier E (2002) Pathways to obesity. Int J Obes Relat Metab Disord 26, S12-S17.

Kumar MV, Moore RL \& Scarpace PJ (1999) $\beta_{3}$-Adrenergic regulation of leptin, food intake, and adiposity is impaired with age. Pflügers Arch 438, 681-688.

Lardy H, Kneer N, Bellei M \& Bobyleva V (1995) Induction of thermogenic enzymes by DHEA and its metabolites. Ann $N Y$ Acad Sci 29, 171-179.

Lee YP \& Lardy HA (1965) Influences of thyroid hormones on $\mathrm{L}-\alpha$-glycerophosphate and other dehydrogenases in various organs of the rat. J Biol Chem 240, 1427-1436.

Leibel RL (2002) The role of leptin in the control of body weight. Nutr Rev 60, S15-S19.

Li H, Matheny M \& Scarpace PJ (1997) $\beta_{3}$-Adrenergic-mediated suppression of leptin gene expression in rats. Am J Physiol 272, E1031-E1036.

Liverini G, Iossa S, Mollica MP, Lionetti L \& Barletta A (1996) Hepatic fatty acid supported respiration in rats fed an energy dense diet. Cell Biochem Funct 14, 283-289.

McCrory MA, Fuss PJ, Saltzman E \& Roberts SB (2000) Dietary determinants of energy intake and weight regulation in healthy adults. J Nutr 130, 276S-279S.

Mollica MP, Iossa S, Liverini G \& Soboll S (1999) Stimulation of oxygen consumption following addition of lipid substrates in liver and skeletal muscle from rats fed high fat diet. Metabolism 48, 1230-1235.

Muller MJ \& Seitz HJ (1984) Thyroid hormone action on intermediary metabolism. I Respiration, thermogenesis and carbohydrate metabolism. Klin Wochenschr 62, 11-18.

Nemeth PM, Rosser BWC, Choksi RM, Norris BJ \& Baker KM (1992) Metabolic response to a high-fat diet in neonatal and adult rat muscle. Am J Physiol 262, C282-C286.

Porte D Jr, Baskin DG \& Schwartz MW (2002) Leptin and insulin action in the central nervous system. Nutr Rev 60, S20-S29.

Pullar JD \& Webster AJF (1977) The energy cost of fat and protein deposition in the rat. Br J Nutr 37, 355-363.

Rolfe DFS \& Brown GC (1997) Cellular energy utilization and molecular origin of standard metabolic rate in mammals. Physiol Rev 77, 731-758.

Rothwell NJ \& Stock MJ (1982) Energy expenditure of "cafeteriafed' rats determined from measurements of energy balance and indirect calorimetry. $J$ Physiol 382, 371-377.

Rothwell NJ, Stock MJ \& Warwick BP (1985) Energy balance and brown fat activity in rats fed cafeteria diets or high-fat, semisynthetic diets at several levels of intake. Metabolism 34, 474-480.

Scarpace PJ, Matheny M, Moore RL \& Tumer N (2000) Impaired leptin responsiveness in aged rats. Diabetes 49, 432-435.

Schwartz MW, Seeley RJ, Campfield LA, Burn P \& Baskin DG (1996) Identification of targets of leptin action in rat hypothalamus. J Clin Invest 98, 1101-1106.

Smith BK, Kelly LA, Pina R, York DA \& Bray GA (1998) Preferential fat intake increases adiposity but not body weight in Sprague-Dawley rats. Appetite 31, 127-139.

Spicer (2002) Effect of high-fat diet on body composition and hormone responses to glucose tolerance tests. Endocrine 19, 327-332.

Tyzbir RS, Kunin AS, Sims NM \& Danforth E (1981) Influence of diet composition on serum triiodothyronine $\left(\mathrm{T}_{3}\right)$ concentration, hepatic mitochondrial metabolism and shuttle system activity in rats. $J$ Nutr 111, 252-259.

Woods SC, Seeley RJ, Rushing PA, D’Alessio D \& Tso P (2003) A controlled high-fat diet induces an obese syndrome in rats. J Nutr 133, 1081-1087.

World Health Organization (1998) Obesity: Preventing and Managing the Global Epidemic. Geneva, Switzerland: World Health Organization. 